\title{
ONLINE MULTI-STAGE MEMBRANE FILTRATION OF SYNTHETIC POLYDISPERSED WATER-SOLUBLE POLYMERS WITH UV VISIBLE ABSORPTION AS A MODE FOR THEIR DETECTION
}

\author{
B.L RIVAS ${ }^{a}$, V.M. SHKINEV ${ }^{b}$, T.G. DZHERAJAN ${ }^{b}$, T.V. DANILOVA ${ }^{b}$,E.D. PEREIRA ${ }^{a}$, A. MAUREIRA ${ }^{a}$ \\ ${ }^{a}$ Faculty of Chemistry, University of Concepción, Casilla 160-C, Concepción, Chile \\ ${ }^{b}$ Vernadsky Institute of Geochemistry and Analytical Chemistry, Russian Academy of Sciences, 117975 Moscow, Russia.
}

(Received: January 4, 2010 - Accepted: January 15, 2010)

\begin{abstract}
This paper reports the application of online membrane filtration with UV visible absorption as a mode of polydispersed substances detection for poly(acryloyl morpholine-co-2-acrylamido-2-methyl-1-propane sulfonic acid), poly[2-acrylamido-2-methyl-1-propane sulfonic acid-co-(3-acryloylamidopropyl) trimethylammonium nitrate), and poly(vinyl alcohol-co-crotonic acid) $10 \%$ of crotonic acid which can be used in medicine and technology. The mass balance in all the cases was not below $100 \pm 7 \%$. The calibration curve are linear at $l_{\text {opt }} 245,230$, and $220 \mathrm{~nm}$ in the interval $0.1-4.0 \mathrm{mg} / \mathrm{mL}, 0.2-3.0 \mathrm{mg} / \mathrm{mL}$ and $0.2-6.0$ $\mathrm{mg} / \mathrm{mL}$, respectively.

It was also used the combination of microfiltration, MF, and gel permeation chromatography, GPC to provide more complete information about the molecular weight distribution of the obtained fractions.
\end{abstract}

Keywords: Water-soluble polymers, ultrafiltration membranes, analysis.

\section{INTRODUCTION}

In the last few years, control of the polymer production process has become especially important due to increased demands for specific qualities by industry as well as for their use in the environment and in medical practice.

Addition polymerization, particularly radical initiation is a synthesis method to obtain polycationic polymers, where oligomers and polymers are at different degrees of polymerization, which can vary in a wide range depending on the synthesis conditions. Additionally, polymers or copolymers often contain other components that cause problems, especially since the investigated polymers were previously designed and tested as metal ion remover and could be used in water purification for either drinking water or residual water. Moreover, they have been tested as biocide against Gram negative and Gram positive bacteria [1-3]. Generally, impurities of the initial monomers, additives, and residual monomers can migrate to the tissue and, depending on the chemical reagent, can cause various tissue responses. The additives may themselves contain various levels of impurities resulting in a potentially large number of compounds available for diffusion into tissue or into a drug solvent system. Additionally, the leached compound can introduce an ingredient that in itself can elicit a pharmacological response. Even, when the leached impurity may not have any appreciable biological activity in other instances, but it may interact with one of the components in the product [4]. The normally used anionic and non-ionic polymers are low toxic, while cationic types are more toxic, especially for aquatic organisms [5,6]. The health significance of possible contaminants has been reviewed in detail $[7,8]$. Generally, the monomers are more toxic than other polymers [6]. Limits on the level of residual monomer are strictly controlled, especially with acrylamide products, where as a general rule the maximum permitted content of free acrylamide is $0.025 \%$ and the residue in drinking water is limited to $0.5 \mathrm{mg} / \mathrm{L}$ [4].

Due to a broad spectrum of polar groups and non-polar fragments, polymers interact between themselves. To better understand the mechanism of these reactions and thus be able to predict the polymer behavior, more detailed information is needed about molecules, structural constituents, molecular size, and degree of polymerization. The better characterization of polydispersed substances, which are complex mixtures of polymers and other products that are sometimes obtained after synthesis, can hardly be achieved without the application of fractionation techniques based on different properties of macromolecules, and especially their size $[9,10]$.

Various separation procedures have been employed for polymers: gel permeation chromatography, membrane filtration to fractionate polymers by their size (molecular weight), electrophoresis, and others. Specially designed online membrane filtration devices were recently tested on polydispersed substances, namely for aquatic humic substances [11-14].

In this paper, we describe the ability of the on-line membrane filtration technique (MF) separation with UV-visible absorption as a mode to detect polydispersed polymers with varying substitutes at main chain.

\section{EXPERIMENTAL}

\section{Reagents}

The following chemicals were used in the experiments: $\mathrm{NaOH}, \mathrm{HCl}, \mathrm{NaCl}$, $\left(\mathrm{NH}_{4}\right)_{2} \mathrm{Cr}_{2} \mathrm{O}_{7}$ (Reakhim, Russia); Tris (Reanal, Hungary); sodium dodecyl sulphate (SDS) (Serva, Germany); Blue dextran 2000 (Pharmacia, Sweden). Acryloyl morpholine, 97\%, Aldrich; 2-acrylamido-2-methyl-1-propane sulfonic acid, 99\%, Aldrich; (3-acryloylamidopropyl) trimethylammonium cloride, $75 \%$, Aldrich. Aqueous solutions of all reagents were prepared using Milli-Q (Millipore) distilled water. Poly(vinyl alcohol-co-crotonic acid) 10 $\%$ of crotonic acid was purchased from Sigma-Aldrich. The stock $5 \mathrm{mg} \mathrm{mL}^{-1}$ polymer solution was prepared by dissolving an exact weighted sample of each polymer in deionized water

Polydisperse substances. Poly(acryloyl morpholine-co-2-acrylamido-2methyl-1-propane sulfonic acid) and poly[2-acrylamido-2-methyl-1-propane sulfonic acid-co-(3-acryloylamidopropyl) trimethylammonium nitrate) were synthesized by radical polymerization as previously described $[15,16]$. Molar masses for both polymers were determined means light scattering, using a Wyatt Dawn DSP-F photometer with a argon laser, and a interferometric refractometer Wyatt Optilab 903. $0.5 \mathrm{M} \mathrm{HCl}$ and $\mathrm{NaNO}_{3}$ solution was used as electrolyte.

Copolymer of a) acryloylmorpholine and 2-acrylamido-2-methyl-1propane sulfonic acid, $\mathrm{Mw}=4.10 \pm 0.60 \cdot 10^{6} \mathrm{~g} / \mathrm{mol}$ (Sample 1)

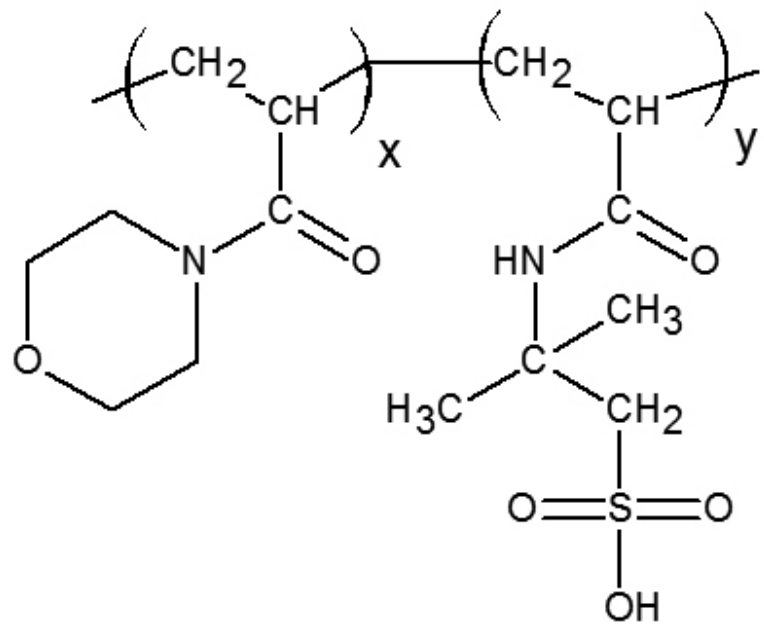


Copolymer of b) 2-acrylamido-2-methyl-1-propane sulfonic acid and (3-acryloylamidopropyl) trimethylammonium nitrate) $\mathrm{Mw}=9.65 \pm 1.00 \cdot 10^{5} \mathrm{~g} /$ mol (Sample 2).<smiles>[X]C(C)(C)C(CC(C)(C)C)C(=O)NCCC[N+](C)(C)[N+](C)(C)[Na]</smiles>

Copolymer of c) of vinyl alcohol and crotonic acid (Sample 3).<smiles>[Y]C(C)C(C(=O)O)C(C)C(C)(C)C([X])(C)C(O)CC(C)(C)C</smiles>

Figure 1. Formula of the studied polymers.

\section{Apparatus}

The membrane filtration studies were made in a completely closed online fractionation device that, after the replacement with the first portion of the sample, provides constant gas balance. The device consisted of five poly(methacrylate) discs with non-spiral channels and bearing $47 \mathrm{~mm}$ Millipore polysulphone membranes with pore sizes of $0.22,0.1,0.05,0.03$ and $0.005 \mu \mathrm{m}$ in the upper part (Eschborn, Germany). The total inner volume of the fractionation device with the pump and connecting tubings was about 15 $\mathrm{mL}$ (Figure 2).
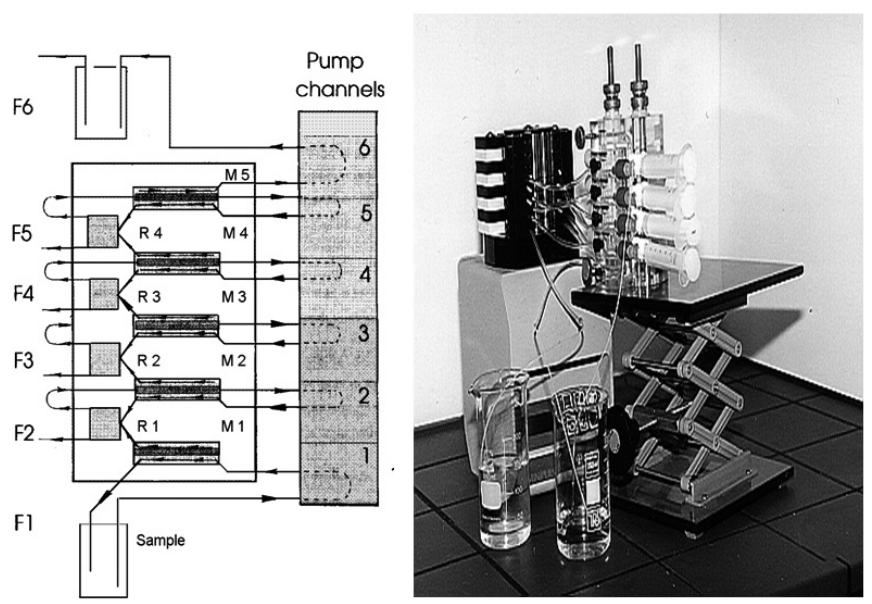

Figure 2. Flow diagram and photo of multistage fractionation device. M-membrane; F-fraction, R-retentate.

The whole fractionation system also included reservoirs for test samples and washing liquids and a multistage peristaltic pump (Gilson Minipuls 3, France), which was equipped with TYGON ${ }^{a}$ tubes of $2.06 \mathrm{~mm}$ I.D. The discs had spiral channels in the upper part, and a drainage system connected with the under-membrane space of the next disc in the lower part. A test sample was fed from a reservoir to the first (lowest) filtration step, where it partially moved in parallel to the membrane surface (tangential flow) before returning to the reservoir and partially through the membrane (filtration flow). The filtrate penetrated into the chamber of the next (upper) disc also partially filtered and partially recirculated; the process was repeated at each next step with a membrane of smaller pore sizes. Special regulating valves were used to control the relatively fast recirculation streams, thus minimising concentration polarisation of solutes at the membrane surfaces [11-12].

Specord UV-VIS was used for UV visible absorption as a mode of detection for polydispersed polymer concentration.

\section{PROCEDURES}

The fractionation system was rinsed with deionized water before each filtration run. The remaining water was displaced from the device by air using the pump applied in all other experiments. After that, the solution was pumped in membrane system. Size classification of polydispersed substances depended on chosen operation parameters. It was found that optimal filtration and circulation flow rates were for speed rotation of pump head equal 60 and $90 \mathrm{rpm}$. Then, filtration and circulation flow rates are determined (Figure 3). So the sample solution was pumped through the device at a filtration rate of $1.4-1.6 \mathrm{~mL} / \mathrm{min}$ and a circulation rate of $0.2-0.6 \mathrm{~mL} / \mathrm{min}$ for $45 \mathrm{~min}$. The ultimate filtrate was again pumped through for another $40 \mathrm{~min}$ to provide better equilibrium between the fractions. Portions of liquid fractions from every filtration stage ( $2 \mathrm{~mL}$ each) were taken from reservoirs after obtaining $30 \mathrm{~mL}$ of the filtrate.

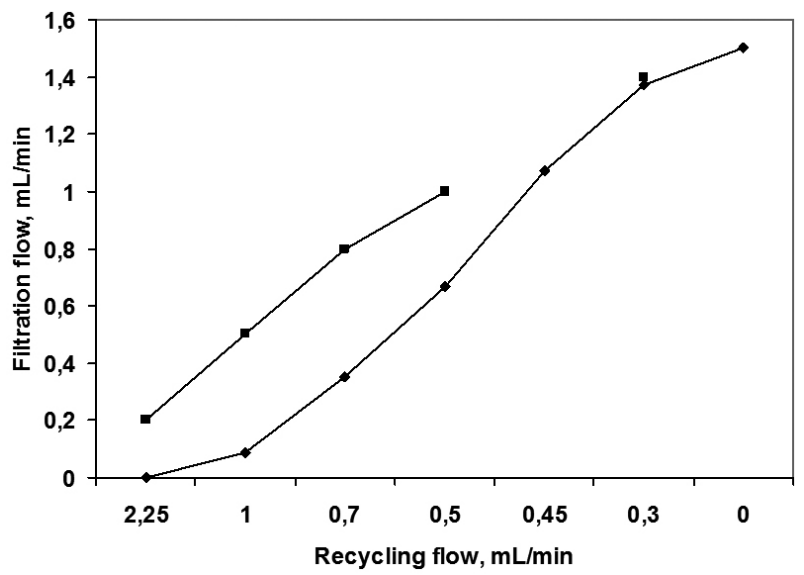

Figure 3. Conditions for fractionation analysis, (u) Rotation speed of pump head $60 \mathrm{rpm}$; (n) Rotation speed of pump head $90 \mathrm{rpm}$.

Molecular weight distributions of polydispersed substances fractionated by GPC were obtained in the K $1.6 \mathrm{~cm}$ ' $70 \mathrm{~cm}$ column ("Pharmacia", Sweden) filled with Sephadex G-75 gel (eluent 0.025 M Tris-HCl buffer $(\mathrm{pH} 8.2)+0.05$ $\mathrm{M} \mathrm{NaCl}+0.1 \% \mathrm{SDS}+0.02 \% \mathrm{NaN}_{3}$, elution rate $8 \mathrm{~mL} / \mathrm{h}$ ). Each column was calibrated by blue dextran 2000 and $\left(\mathrm{NH}_{4}\right)_{2} \mathrm{Cr}_{2} \mathrm{O}_{7}$ solutions in the eluent buffer to determine a column void volume and a total gel bed volume, respectively.

To obtain the calibration curves for the UV visible spectrophotometric determination of the polymers series, solutions for each stock solution of initial polymer were prepared in $5 \mathrm{~mL}$ volumetric test tubes. Between 0.1 and $1.0 \mathrm{~mL}$ of stock solutions of $2 \mathrm{mg} \mathrm{mL}^{-1}$ at $\mathrm{pH} 5-6$ were added and diluted to $5 \mathrm{~mL}$ with deionized water, mixed thoroughly, and the optical density of obtained solution was measured at optimum for each polymer 1 , relative to deionized water. It was carried out in a $1 \mathrm{~cm}$ cuvette.

\section{RESULTS AND DISCUSSION}

Results for the three different fractionated samples and their metrological evaluation are shown in Table 1. The mass balance was calculated as a ratio of the polymer's total concentration in all fractions to its initial concentration in the corresponding sample. The mass balance in all the cases presented was not below $100 \pm 7 \%$.

The calibration curves are linear at $1_{\text {on }} 245,230$, and $220 \mathrm{~nm}$ in the interval $0.1-4.0 \mathrm{mg} / \mathrm{mL}, 0.2-3.0 \mathrm{mg} / \mathrm{mL}$ and $0.2-6.0 \mathrm{mg} / \mathrm{mL}$ for samples 1,2 , and 3 respectively. The equations of calibration graphs and regression coefficients (R) for sample number 1,2 , and 3 are: $A_{1}=0.206 c+0.046(0.9)$, 
$A_{2}=0.511 c+0.066(0.9)$, and $A_{3}=0.186 c+0.013(0.9)$ respectively.

Table 1. Results of polyvinyl determination in fractions $\mathrm{F}_{1}(<0.003 \mu \mathrm{m})$, $\mathrm{F}_{2}(0.0030 .03 \mu \mathrm{m}), \mathrm{F}_{3}(0.03-0.05 \mu \mathrm{m}), \mathrm{F}_{4}(0.05-0.1 \mu \mathrm{m}), \mathrm{F}_{5}(0.1-0.22 \mu \mathrm{m}), \mathrm{F}_{6}$ $(>0.22 \mu \mathrm{m}), \mathrm{n}=3, \mathrm{P}=0.95)$.

\begin{tabular}{|c|c|c|c|c|}
\hline \multicolumn{2}{|c|}{ Sample number } & 1 & 2 & 3 \\
\hline \multicolumn{2}{|c|}{ Added, mg } & 55.0 & 90.0 & 25.0 \\
\hline \multirow{12}{*}{$\begin{array}{l}\text { Found in } \\
\text { fractions }\end{array}$} & $\mathrm{F}_{1}$ & 0.0 & $35.0 \pm .5 .9$ & 0.0 \\
\hline & $\mathrm{S}_{\mathrm{r}}$ & - & 0.10 & - \\
\hline & $\mathrm{F}_{2}$ & $2.00 \pm 0.26$ & $12.60 \pm 3.64$ & $1.40 . \pm .0 .52$ \\
\hline & $\mathrm{S}_{\mathrm{r}}$ & 0.06 & 0.13 & 0.16 \\
\hline & $\mathrm{F}_{3}$ & $2.98 \pm 0.30$ & $2.10 \pm 0.39$ & 5.63.土.0.90 \\
\hline & $\mathrm{S}_{\mathrm{r}}$ & 0.045 & 0.080 & 0.074 \\
\hline & $\mathrm{F}_{4}$ & $3.55 \pm 0.65$ & $6.40 \pm 2.34$ & $6.13 . \pm .0 .65$ \\
\hline & $\mathrm{S}_{\mathrm{r}}$ & 0.083 & 0.160 & 0.057 \\
\hline & $\mathrm{F}_{5}$ & $5.10 \pm 0.90$ & $24.43 \pm 3.38$ & $1.45 . \pm .0 .35$ \\
\hline & $\mathrm{S}_{\mathrm{r}}$ & 0.14 & 0.06 & 0.11 \\
\hline & $\mathrm{F}_{6}$ & $40.6 \pm 6.50$ & $2.27 \pm 1.17$ & 8.43.土.1.69 \\
\hline & $\mathrm{S}_{\mathrm{r}}$ & 0.07 & 0.23 & 0.10 \\
\hline \multicolumn{2}{|c|}{ Found in sum, mg } & $54.2 \pm 4.5$ & $82.8 \pm 8.4$ & $23.2 \pm 2.3$ \\
\hline \multicolumn{2}{|l|}{$\mathrm{S}_{\mathrm{r}}$} & 0.04 & 0.05 & 0.04 \\
\hline
\end{tabular}

A supplementary size classification by a reference method (e.g. GPC) is recommended [8-10]. We use the combination of MF and GPC to provide more complete information about the molecular weight distribution of the obtained fractions. Due to the large dilution of samples during MF, only quality characteristics for sample 2 were obtained. Their concentration appears to be outside of the GPC method's limit of sensitivity. The initial sample concentrations could not be increased due to the large increase in viscosity. Qualitative GPC analysis of sample No 2 fractions showed a relative homogeneity increase from the initial sample to the filtrate.

Table 2. Polyvinyl content (\%) in the fractions after membrane filtration.

\begin{tabular}{|c|c|c|c|c|}
\hline \multirow{2}{*}{$\begin{array}{c}\text { Fraction } \\
(\text { No) }\end{array}$} & $\begin{array}{c}\text { Pore size } \\
\text { Mkm }\end{array}$ & \multicolumn{3}{|c|}{ Polymer content in fractions (\%) } \\
\cline { 3 - 5 } & $\begin{array}{c}\text { Sample } \\
\text { No 1 }\end{array}$ & $\begin{array}{c}\text { Sample } \\
\text { No 2 }\end{array}$ & $\begin{array}{c}\text { Sample } \\
\text { No 3 }\end{array}$ \\
\hline $\mathrm{F}_{6}$ & $<0.003$ & 0.0 & 42.3 & 0.0 \\
\hline $\mathrm{F}_{5}$ & $0.003-0.03$ & 3.9 & 15.2 & 6.7 \\
\hline $\mathrm{F}_{4}$ & $0.03-0.05$ & 5.9 & 2.5 & 26.7 \\
\hline $\mathrm{F}_{3}$ & $0.05-0.1$ & 7.0 & 7.7 & 24.5 \\
\hline $\mathrm{F}_{2}$ & $0.1-0.22$ & 10.0 & 29.5 & 6.9 \\
\hline $\mathrm{F}_{1}$ & $>0.22$ & 79.9 & 2.7 & 35.4 \\
\hline
\end{tabular}

According to the data of MF (Table 2), the polymer in sample 2 is the only one of three investigated that was determined in the fraction $\mathrm{MM}<30$ $\mathrm{kDa}$. Analysis of this fraction by the GPC method showed that there are not only molecules with $\mathrm{MM}<30 \mathrm{kDa}$, but also molecules with $\mathrm{MM}>75 \mathrm{kDa}$. This phenomenon might be explained by considering the possibility of molecule conformation changes during the MF process. Thus, molecules (MM>75 kDa) with long-chain substitutes have the architecture to penetrate through the membrane corresponding to $\mathrm{MM}<30 \mathrm{kDa}$.

As can be seen in the MF data (Table 2), approximately $80 \%$ of the sample 1 polymer was determined in the fraction corresponding to an MM about 2200 $\mathrm{kDa}$, which could be explained as a result of synthesis. However, it cannot be excluded the explanation that the molecule conformation changed when it contains some morpholine substitutes.

MF analysis of polymer sample 3 showed that its molecules are equally distributed between first, third, and fourth fractions (Table 2). Thus, one could assume that polymer sample 3 consists of a mixture of polymers with MM from 300 to $2200 \mathrm{kDa}$ and greater.

\section{CONCLUSIONS}

On-line membrane filtration method and following it spectrophotometric analysis is very useful for the purposes of water-soluble polymer separation and fractionation and their spectrophotometric analysis because of its reliable and reproducibility.

It is very important establish that this procedure was used by the first time for analysis of real water-soluble polymer synthetic samples.

Acknowledgements

The authors thank to FONDECYT (Grant No 1070542), Anillo ACT 130, CIPA, and RFFR (Grant No 07-03-00743)

\section{REFERENCES}

1. Kenawy E-R. (2001) Biologically active polymers. IV. Synthesis and antimicrobial activity of polymers containing 8-hydroxyquinoline moiety. J App Polym Sci 82(6): 1364-1374.

2. Nishikawa M, Ogawa K. (2004) Antimicrobial Activity of a Chelatable Poly(arginyl-hystidine) produced by the Ergot Fungus Verticillium kibiense. Antimicrob Agents Chemother, 48(1): 229-235.

3. Hu FX, Neoh KG, Cen L, Kang E.T. (2005) Antibacterial and antifungal efficacy of surface functionalized polymeric beads in repeated applications. Biotech Bioeng 89(4): 474-484

4. Sideridou ID, Achilias DS (2005) Elution study of unreacted Bis-GMA, TEGDMA, UDMA, and Bis-EMA from light-cured dental resins and resin composites using HPLC. J Biomed Mat Res Part B: Appl Biomat 74B(1): 617-626

5. Rowland CD, Burton GA, Morrison SM (2000) Implication of polymer toxicity in a municipal wastewater effluent. Environ Toxicol Chem 19(8): 2136-2139

6. Criddle J (1990) A review of the mammalian and aquatic toxicity of polyelectrolytes. Report NR 2545, Medmenham, Foundation for Water Research

7. Bolto B, Gregory J (2007) Organic polyelectrolytes in water treatment. Water Res 41(11): 2301-2324

8. Letterman RD, Pero RW (1990) Contaminants in polyelectrolytes used in water treatment. J Amer Water Works Assoc 82(11): 87-97

9. Rivas BL, Pereira ED, Mondaca MA, Rivas RJ, Saavedra MI (2003) Water-soluble cationic polymers and their polymer-metal complexes with biocidal activity: A genotoxicity study, J Appl Polym Sci 87(3): 452-457

10. Rivas BL, Pereira ED, Mondaca MA (2003) Biostatic Behavior of Side Chain Charged Polycations and Polymer-Ag Complexes. Polym Bull 50(5-6): 327-333

11. Burba P, Aster B, Nifantieva T, Shkinev VM, Spivakov B (1998) Membrane filtration studies of aquatic humic substances and their metal species: a concise overview: Part 1 . Analytical fractionation by means of sequential-stage ultrafiltration. Talanta 45(5): 977-988

12. Nifantieva T, Shkinev VM, Spivakov B, Burba P (1999) Membrane filtration studies of aquatic humic substances and their metal species: a concise overview. Part 2. Evaluation of conditional stability constants by using ultrafiltration. Talanta 48(2): 257-267

13. Zavarzina AG, Demin VV, Nifantieva TI, Shkinev VM, Danilova TV Spivakov BY (2002) Extraction of humic acids and their fractions in poly(ethylene glycol)-based aqueous biphasic systems. Anal Chim Acta 452(1): 95-103

14. Wennrich R, Mattusch J, Morgenstern P, Dzherayan TG, Shkinev VM, Spivakov BY (1997) Size and phase fractionation of water components by membrane filtration Distribution patterns for arsenic, iron and manganese in aqueous effluents of tin ore settling plant. Fresenius J Anal Chem 359(2): 161-166

15. Rivas BL, Pereira ED, Moreno-Villoslada I (2003) Water-soluble polymer-metal ion interactions. Prog Polym Sci 28(2): 173-208

16. Rivas BL, Maureira A, Geckeler KE, (2006) Novel water-soluble acryloylmorpholine copolymers: Synthesis, characterization, and metal ion binding properties J Appl Polym Sci 101(1): 180-185. 